\title{
USO DE TECNOLOGIAS EDUCACIONAIS POR PROFESSORES NO ENSINO SUPERIOR: REFLEXÕES A PARTIR DE UM FÓRUM DE DISCUSSÕES
}

\author{
CURITIBA/PR MAIO/2018
}

\author{
KARINA NONES TOMELIN - UP - karina.tomelin@up.edu.br \\ SIOMARA CORTIANO - UP - siomara.cortiano@up.edu.br \\ JULIANA TIBAES - UP - juliana.tibaes@up.edu.br \\ JOSIANE RABAC - UP - josiane.rabac@up.edu.br \\ ADRIANA PELIZZARI - UP - adriana.pelizzari@up.edu.br
}

\author{
Tipo: Relato de Experiência Inovadora (EI) \\ Categoria: Métodos e Tecnologias \\ Setor Educacional: EDUCAÇÃO SUPERIOR
}

\begin{abstract}
RESUMO
O objetivo deste trabalho é relatar a experiência de vinte e nove professores de educação superior com relação ao uso de tecnologias educacionais na sala de aula. As experiências foram relatadas em um fórum de discussão de uma comunidade de professores de uma universidade privada de Curitiba. O foco do debate foi conhecer quais recursos são conhecidos e utilizados entre os docentes e favorecer o compartilhamento destas ferramentas. O fórum compõe atividade avaliativa de um curso de formação docente institucional. O resultado indicou o mapeamento de trinta recursos conhecidos pelos docentes. O compartilhamento mobilizou o interesse por dezenove ferramentas que ainda eram desconhecidas pelos demais. A experiência demonstrou que a maioria dos professores reconhece a necessidade de utilização de recursos tecnológicos para motivar a aprendizagem de seus alunos. Também se sentem motivados a utilizá-los, especialmente quando o recurso é apresentado por um dos pares.
\end{abstract}

Palavras-chave: tecnologia educacional, ensino superior, recursos de aprendizagem 


\section{INTRODUÇÃO}

O uso das tecnologias educacionais tem se revelado um ótimo recurso de ensino e aprendizagem aos docentes em todos os níveis educacionais. Dentre as vantagens está especialmente a motivação discente pelo processo de ensino e aprendizagem.

O professor, mesmo com pouca intimidade ou muita dificuldade na utilização de tais recursos, vê a necessidade de se aproximar e aprender a utilizá-los. Nas universidades, os ambientes virtuais de aprendizagem já são ferramentas disponíveis e de acesso necessário a maioria dos docentes, não somente da EAD.

Mas, além disso, quais outros recursos os professores universitários têm utilizado para potencializar o processo de ensino e aprendizagem de seus alunos? Quais deles despertam mais interesse do estudante? E quais recursos são os mais preferidos pelos docentes?

O objetivo deste estudo é apresentar os recursos tecnológicos mais utilizados por docentes universitários indicando sua preferência e motivação em aprender a utilizá-los.

\section{TECNOLOGIAS E EDUCAÇÃO}

Vivemos um momento de mudanças surpreendentes. Elas também têm impactado a educação não somente pela criação e disseminação de novos recursos de aprendizagem, como também na interlocução com seus próprios atores. Os jovens alunos, nativos digitais, interagindo com docentes, eminentemente imigrantes digitais.

A modernidade sólida dá lugar à modernidade líquida e esta passagem traz profundas mudanças em todos os aspectos da vida humana. A arte de viver em um mundo ultrassaturado de informações que ainda devem ser aprendidas torna-se um desafio também quando se trata do papel de educar neste novo modo de viver, comenta o filósofo Zigmund Baumam em entrevista sobre educação e modernidade líquida. (PORCHEDDU, 2009) 
O professor tem grandes desafios nas salas de aulas dos dias de hoje. E ele tem consciência de que o desafio maior é motivar o estudante para o processo de ensino e aprendizagem. Também sabe que a tecnologia pode ser um agente potencializador da motivação para a aprendizagem. Segundo Prensky (2012) o que diferencia um professor como ótimo instrutor é a habilidade de envolver os estudantes no processo de aprendizagem principalmente na sua motivação.

Reconhecer o papel da tecnologia faz com o que o professor ganhe mais tempo para se dedicar a melhorar suas estratégias de ensino e, também, de se relacionar com seus alunos favorecendo a personalização do processo de ensino e aprendizagem.

A tecnologia educacional aparece como campo de estudo, segundo Richter e Anderson (2015) a partir do início do século XIX, com um crescente nas décadas de 60 e 80, culminando com os avanços dos últimos dez anos. O uso da tecnologia na educação está muito associado ao desenvolvimento e apoio dos processos de ensino e aprendizagem indicando a forma como professores e alunos interagem e se comunicam. Elas incluem novas mídias sociais, mundo virtuais, tecnologias baseadas em games e tecnologias aumentadas e gestuais.

Segundo o Censo da Abed (2016), na educação a distância os estudantes utilizam diferentes tecnologias para participar dos cursos. Desta forma, a maioria das instituições oferece internet e computadores aos alunos. E os alunos de cursos regulamentados totalmente a distância são os que mais têm acesso à internet e a computadores na sede ou nos polos: em $84 \%$ das instituições.

É inegável o impacto crescente das tecnologias educacionais na educação. Porém, somado aos desafios tecnológicos ainda estão os desafios entre gerações. Marc Prensky, pensador norte-americano, chama de "nativos digitais" os que pertencem a? geração que sabe falar a língua da tecnologia digital, com os computadores, os videogames, a internet. Os que começaram a usar essa linguagem mais tarde na vida, com mais ou menos entusiasmo, são os "imigrantes digitais".

O imigrante digital sempre conserva algum sotaque e tem lembrança da cultura anterior, em que foi socializado. Ainda lê manuais, imprime textos para ler, telefona para perguntar se o e-mail enviado foi recebido e outros tantos exemplos que denunciam outra cultura de formação. A escola lida com o problema complexo do encontro de dois grupos (os estudantes nativos digitais e os educadores imigrantes) que interpretam o real de modo diferente e usam línguas diferentes. (SILVA, 2013) 
A tecnologia digital e seus avanços estão no cerne da problemática das transformações no mundo de hoje. Isto é fato. No entanto, uma outra reflexão há que se fazer, a fim de não se deixar trair por concepções equivocadas. O profundo conhecimento da tecnologia ou o uso de tecnologias avançadas em sala de aula formaria um professor do século XXI?

As transformações trazidas pela tecnologia sobre a qual tanto falamos e discutimos mudou as exigências de aprendizagem de nossos alunos, mudou também o perfil do profissional que o mercado deseja.

É por isto que dizemos que a educação superior tem que dar conta, no mínimo, de dois grandes desafios: assegurar que a educação vá ao encontro das expectativas dos estudantes e as exigências do mercado, tanto para hoje como para o futuro. Se para hoje já não é uma tarefa fácil, como fazer para preparar profissionais para situações que ainda nem existem?

\section{O PAPEL DO PROFESSOR}

José Moran (2000), professor e autor conhecido por tratar de temas relacionados à educação, tecnologia e comunicação, em seu artigo "mudar a forma de ensinar e aprender", defende que o ideal na educação atual, é a convergência entre momentos presenciais coletivos e estudos individuais, tratando do que hoje chamamos de ensino híbrido.

Além disto, ele traz uma descrição muito clara sobre o papel do professor nos dias atuais: O professor é aquele que coordena os grandes temas para discussão, quem motiva o aluno, quem desperta a curiosidade e a aprendizagem a qual deve ser vista como processo contínuo de comunicação e pesquisa. Ao descrever a importância de educar o docente, ele resume bem o papel do professor quando diz:

As mudanças na educação dependem, em primeiro lugar, de termos educadores maduros intelectual e emocionalmente, pessoas curiosas, entusiasmadas, abertas, que saibam motivar e dialogar. Pessoas com as quais valha a pena entrar em contato, porque dele saímos enriquecidos. (MORAN, 2000, p.5) 
O papel do professor vai além da previsibilidade, da repetição de fórmulas ou sínteses. O contato com educadores entusiasmados atrai, contagia, estimula e os aproxima da maior parte dos alunos. Isto porque são professores preocupados não somente com 0 processo de ensino, mas também com o de aprendizagem. Pensar no uso de tecnologias e associá-las as metodologias ativas tem sido um caminho possível a maioria dos "docentes do século XXI".

As metodologias ativas de ensino surgem neste cenário em contraposição à forma tradicional de ensinar, focada na transmissão de conteúdos e na atitude passiva do estudante. Na perspectiva da aprendizagem ativa, o estudante é responsável pelo seu processo de aprender, e os resultados dependem de sua postura atuante e proativa. $\mathrm{O}$ professor, por sua vez, realiza sua função de instigar, de propor problemas, de discutir soluções, de trocar ideias, de incitar a reflexão. O professor tem como função planejar atividades que permitam ao estudante realmente chegar ao resultado previsto nos objetivos de aprendizagem, seja resolver um problema, fazer uma análise, desenvolver um projeto.

O propósito das metodologias ativas é transferir o foco das aulas para um momento de interação, de trabalho individual ou em equipe, de interlocução com o professor, de troca de experiências, de solução de problemas e não de transmissão de conteúdo. E é neste aspecto que a tecnologia tem um papel fundamental, permitindo a disponibilização prévia de conteúdos aos alunos, por meio de diversos recursos digitais, como textos, áudios, vídeos, e-books e todo o conteúdo disponível na web, acessado via internet.

Dentre as metodologias ativas mais conhecidas e utilizadas estão: Instrução por pares (Peer Instruction); Sala de Aula Invertida (Flipped classroom); Aprendizagem baseada em problemas (Problem-based learning); Aprendizagem baseada em projetos (Project-based learning); Aprendizagem por pesquisa e Estudo de caso.

\section{RESULTADOS}

As estratégias de formação docente entre pares são muito ricas e produtivas especialmente quando realizadas por meio de ambientes virtuais de aprendizagem. (TOMELIN, 2016). Isto porque ela é mais facilmente legitimada pelos professores. 
Um dos módulos do curso "Competências do professor do Século XXI" ofertado aos docentes de uma universidade privada de Curitiba discutia sobre a influência da tecnologia no processo de ensino e aprendizagem. O desafio proposto aos professores no fórum era o compartilhamento de um recurso digital como: animação, aplicativo, software, ferramenta, game, simulador... utilizados pelos docentes em sala de aula.

Vinte e nove professores compartilharam um ou mais recursos utilizados. O gráfico a seguir descreve os recursos mais utilizados pelos docentes e os que mais geraram interesse pelos que os desconheciam.

\section{Uso de ferramentas}

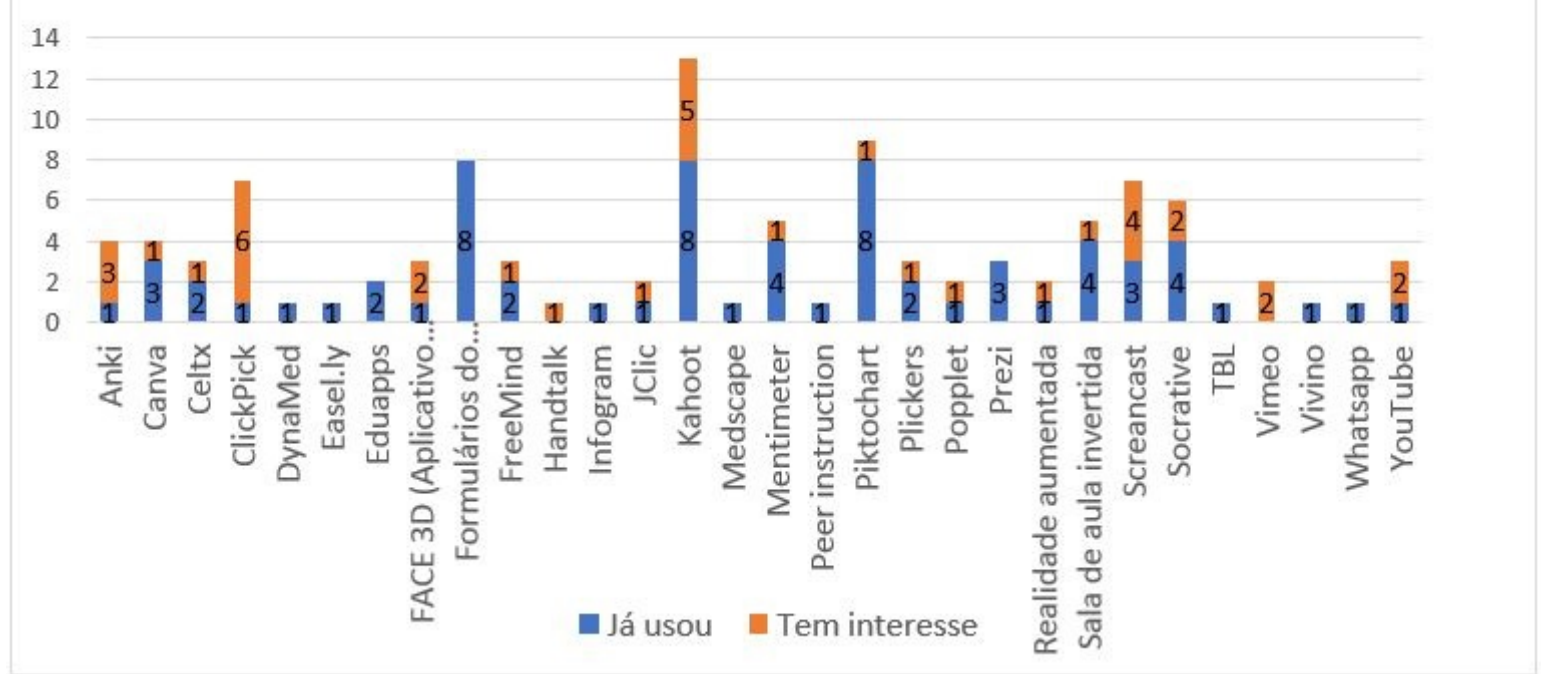


É possível observar que alguns professores pesquisados classificaram determinadas metodologias ativas como recurso digital, esses dados serão desconsiderados nesta análise. Portanto, os 26 recursos apresentados na pesquisa podem ser classificados em quatro categorias de acordo com a sua utilização: ferramentas para facilitar o processo de ensino-aprendizagem (a), comunicação com os alunos (b), ferramentas de exposição de conteúdo (c) e ferramentas de acessibilidade (d).

Em (a), podemos considerar os recursos que auxiliam o docente a reforçar 0 aprendizado da competência de forma interativa, tais como realidade aumentada, modelos 3D, jogos e construção de mapas mentais.

Nessa pesquisa, ganhou destaque o software Kahoot, que é uma plataforma de aprendizagem baseada em jogos, onde o docente consegue aplicar um questionário em tempo real aos seus alunos e mensurar o resultado assim que terminarem as questões. Também foram citadas as ferramentas Socrative, Jclic, Mentimeter e Picklers que funcionam de forma similar e com o mesmo propósito. O Google Formulário, apesar de não ser uma ferramenta de gameficação do aprendizado, foi utilizada para a elaboração de formulários contendo exercícios e quiz podendo o docente visualizar as respostas e obter gráficos dos resultados das questões objetivas.

Outra ferramenta que teve destaque foi o uso do Anki, que é um software gratuito para a memorização de cartões virtuais. Esses cartões podem ser elaborados pelo docente ou por algum aluno e disponibilizado aos alunos para auxiliá-los a estudarem sobre um determinado conteúdo. Vale lembrar que essa metodologia é muito eficaz apenas para conteúdos os quais precisam ser memorizados, tais como o aprendizado de idiomas, leis, locais e pessoas.

O FreeMind é um software gratuito para elaboração de mapas mentais, onde o aluno ou o docente poderão elaborar o mapa sobre o conteúdo abordado. Embora nenhum dos docentes tenha citado outro software nessa pesquisa, é importante lembrar que o FreeMind não é o único e nem pode ser considerado o melhor software de mercado 
nessa área, visto que existem vários outros com a mesma proposta, tais como Mind Meister, Mind Node, Xmind, Free Plane, Mind Mapr, Coggle e outros.

Para estudos da anatomia da cabeça, destacou-se o Face 3D, que é um aplicativo para a visualização de um modelo tridimensional de um crânio. Esse software foi desenvolvido pela própria universidade para estudos principalmente da área de odontologia. Outros recursos da área da saúde apresentados foram o DynaMed e o Medscape, que são ferramentas para a pesquisa e visualização de informações sobre medicina.

Em (b), foram considerados todos os recursos que visam facilitar a comunicação entre discentes e docente, dentro e fora de sala de aula. Nessa pesquisa, teve destaque o WhatsApp, que pode ser utilizado para a comunicação do docente com os alunos em um grupo da disciplina ou turma, tanto para a comunicação dos alunos entre seus pares para a confecção de projetos ou até mesmo para a disponibilização de materiais, como artigos e vídeos. Também foi citado o EduApps, que é uma plataforma para a criação de aplicativos móveis, onde o docente é capaz de elaborar seu conteúdo personalizado e disponibilizá-lo aos seus alunos.

A fim de expor o conteúdo aos alunos ou auxiliar os alunos a elaborarem suas apresentações, classificado como (c), várias ferramentas foram citadas, desde aplicativos para elaboração do conteúdo do que será apresentado até a forma em que será exposto. Nesse cenário, o Prezi ganhou destaque e seu concorrente da Microsoft, o PowerPoint, sequer foi citado. Para a elaboração de gráficos e infográficos, foram apresentados os Canva, Infogram e o Picktochart.

De acordo com esta pesquisa, o Youtube e o Vimeo são plataformas utilizadas tanto para disponibilizar conteúdos extra aos alunos quanto para a apresentação de trabalhos elaborados pelos alunos. Para elaborar a montagem de forma simples do vídeo e/ou o roteiro do vídeo, destacou-se o Celtx. E o Screencast para a captura de tela do computador.

Em (d) é possível considerar toda ferramenta que facilite a interação entre alunos com necessidades especiais e o docente. Nesta pesquisa, foi apresentada apenas um aplicativo por um docente: o Handtalk. Este, tem como objetivo fazer a tradução de textos, sites e áudios para a Libra (linguagem de sinais brasileira).

Recentemente um novo estudo sobre o ensino híbrido foi publicado pela Clayton Christensen Institute. Dentre outras questões, o estudo se propôs a conhecer os 
principais softwares e recursos de aprendizagem digital utilizados pelos docentes. No Brasil, entre os softwares mais citados estão produtos do Google, com $26,5 \%$ de respostas, e Khan Academy, 14,5\%. Em seguida, vieram sites específicos das redes de ensino, YouTube, Microsoft e Code.org. De acordo com o levantamento, $58,2 \%$ dos entrevistados respondeu que os alunos passam de 0 a $25 \%$ da semana em aprendizagem online; $29,1 \%$ disseram que a porcentagem vai de $26 \%$ a $50 \% ; 8,2 \%$ afirmaram que é de $51 \%$ a $75 \%$; e $4,5 \%$ disseram que os estudantes passam de $76 \%$ a $100 \%$ do tempo online. (NOGUEIRA, 2018)

\section{CONSIDERAÇÕES FINAIS}

Os educadores, muitos imigrantes digitais, sabem da necessidade da mudança, ou se não sabem, percebem o movimento neste sentido. Muitos manifestam o desejo de compreender como a tecnologia pode ajuda-los a melhorar o processo de ensino e aprendizagem.

Por outro lado, diante de tantas ferramentas, nomenclaturas, o professor tem dificuldade em selecionar quais são mais produtivos e eficazes considerando o perfil de estudantes e, também, dos recursos tecnológicos disponíveis na instituição que atua.

Promover o aprendizado entre pares para potencializar e otimizar a utilização de recursos tecnológicos pode ser uma estratégia eficiente para a introdução de novas ferramentas de ensino.

\section{REFERÊNCIAS}

CENSO EAD: Relatório analítico da aprendizagem a distância no Brasil 2016. São Paulo, ABED, 2016. Disponível em http://dx.doi.org/10.1590/S0100-15742009000200016.

MORAN, J. Mudar a forma de ensinar e aprender. Revista Interações, São Paulo, 
2000. vol. $\quad$ V, $\quad$ p.57-72, disponível em http://www.eca.usp.br/prof/moran/site/textos/tecnologias_eduacacao/uber.pdf

NOGUEIRA, Fernanda. Formação do professor é o maior desafio para uso de tecnologia, mostra estudo. 27/04/2018. Artigo disponível em http://porvir.org/formacaodo-professor-e-o-maior-desafio-para-uso-de-tecnologia-mostra-estudo/.

PORCHEDDU, Alba. Zygmunt Bauman: Entrevista sobre a educação. Desafios pedagógicos e modernidade líquida. Cad. Pesquisa, São Paulo, v. 39, n. 137, p. 661-684, Aug. 2009. Disponível em <http://www.scielo.br/scielo.php?script=sci_arttext\&p id $=$ S0100-15742009000200016\&lng=en\&nrm=iso $>$. Acessado em 19/09/2018

PRENSKY, M. Aprendizagem baseada em jogos digitais. São Paulo: Senac, 2012.

RICHTER, O. Z. ANDERSON, T. (org) Educação a Distância Online. Construindo uma agenda de pesquisa. São Paulo: Artesanato Educacional: 2015.

SILVA, P. A escola na era digitalin Vivendo esse mundo digital. Organizadores: ABREU, Cristiano N. de et al. (pág. 132-141). Porto Alegre, Rio Grande do Sul: Artmed, 2013.

TOMELIN, K. N. TOMELIN, J. F. Mentoring: experiências na formação de professores presenciais em ambiente virtual de aprendizagem. Disponível em $<$ http://www.abed.org.br/congresso2016/trabalhos/235.pdf> acesso em 19 de maio de 2018. 